\title{
POLÍTICAS ARQUIVÍSTICAS E SUAS IMPLICAÇÕES NA PRESERVAÇÃO, NO ACESSO E NO USO DOS DOCUMENTOS
}

\author{
THE ARCHIVE POLICIES THE YOUR IMPLICATIONS IN PRESERVATION, IN ACCESS \\ AND IN USE OF DOCUMENTS
}

Rose Tenório de Oliveira

Arquivista. FIOCRUZ. Especialista em Organização, Planejamento e Direção de Arquivos pelo convênio UFF/AN.

oliveyra@fiocruz.br

\section{Resumo}

Este estudo propõe discutir as implicações que a inexistência de políticas arquivísticas pode ter na preservação de acervos documentais. Leva em consideração que a preservação documental tem como objetivo garantir o acesso e o uso dos documentos, uma vez que o manuseio incorreto durante uma pesquisa é um dos vários fatores degradantes que afetam os acervos. Procura elencar tanto as dificuldades existentes nesse campo, quanto explicar que a preservação documental consiste em um trabalho de gestão onde o que está em jogo é o planejamento para definição de prioridades de ação.

Palavras-chave: Preservação Documental. Políticas de arquivo. Acesso. Uso. Arquivologia.

\section{INTRODUÇÃO}

No mundo inteiro, arquivistas, bibliotecários, museólogos e conservadores têm lidado com a preocupação quanto à preservação dos testemunhos históricos e culturais, também chamado de patrimônio. No Brasil, este termo encontra lugar na Constituição Federal de 1988, onde, no Art. 216, fica estabelecido que "constituem patrimônio cultural brasileiro os bens de natureza material e imaterial, tomados individualmente ou em conjunto, portadores de referência à identidade, à ação, à memória dos diferentes grupos formadores da sociedade brasileira" (BRASIL, 1988), dentre os quais se incluem também os acervos documentais. Cada um desses profissionais certamente tem orgulho desse patrimônio e anseia por the dar o melhor tratamento possível, afinal, esta é a sua tarefa. Como reforça García Belsunce:

\begin{abstract}
O patrimônio documental contido nos arquivos é matéria nutriente da informação primária [...]. Ao dar relevância à funcionalidade, estamos possibilitando, quase exigindo, um novo tratamento administrativo do documento [...]. Essa função informativa e os múltiplos usos derivados dela exigem uma particular proteção do patrimônio documental (BELSUNCE, 1986, p. 31 apud SILVA, 1998, p. 27).
\end{abstract}

Numa corrida contra o tempo, preservar o patrimônio contido nos arquivos tornou-se, inexoravelmente, mais que um dever. É uma obrigação que se encontra no bojo das

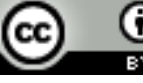
DOI 10.5007/1518-2924.2011v16nesp1p60 
atribuições dos profissionais acima mencionados. Mas, diante do imenso volume de documentos que se acumulam nos arquivos, o que preservar? Ou melhor, o que eleger para uma vida mais longa? O que condenar à morte, se certa é a impossibilidade da preservação integral? Tarefa árdua a dos responsáveis pela preservação deste patrimônio.

O patrimônio documental é feito de matéria orgânica - animal ou vegetal (pergaminho ou papel) e, como tal, é passível de deterioração. Assim como um ser vivo, esse patrimônio nasce, vive e morre. O que arquivistas e conservadores tentam incansavelmente fazer é retardar essa morte. Sem falar nos acervos digitais, cuja preservação ainda é um grande desafio.

A preservação, segundo o professor Sergio Albite Silva (1998, p. 9), “deve ser entendida, hoje em dia, pelo seu sentido geral e abrangente. Seria então, toda ação que se dedica a salvaguardar ou a recuperar as condições físicas e proporcionar permanência aos materiais dos suportes que contêm a informação". Esta situação implica em muitas decisões, desde as relacionadas especificamente ao fazer arquivístico - recolhimento do acervo, classificação, avaliação e seleção de documentos, etc; até as de higienização, acondicionamento e outras que são da alçada de conservadores.

Todos esses aspectos se impõem cotidianamente e as técnicas necessárias à execução dessas atividades estão ao dispor dos profissionais, algumas serão utilizadas isoladamente, outras em conjunto, tendo como objetivo único prolongar a vida de alguns documentos, jamais de todos. Pois, por mais boa vontade e recursos que existam, nem tudo poderá ser preservado. O próprio manuseio incorreto durante uma pesquisa é um dos vários fatores degradantes que afetam os documentos. Porém, quando não é possível intervir em todas as frentes com a mesma uniformidade, para prover acesso, garantindo a preservação do acervo, torna-se indispensável diagnosticar o conjunto da instituição e, cautelosamente, decidir como agir. Já que sempre haverá uma escolha a ser feita e uma decisão a ser tomada. “[...] Em um programa responsável de administração arquivística, a preservação é um componente que deve estar inserido na missão, nas políticas, e nas ações [da instituição]” (BECK, 2006, f. 18).

É neste sentido que se justifica a realização deste estudo: Entender as implicações que a inexistência de uma política arquivística de acesso formalmente constituída e explícita pode ter no âmbito da preservação do acervo arquivístico, uma vez que decisões tomadas isoladamente não podem ser vistas como políticas. Entretanto, a repetição sistemática de certas decisões pode ser assim interpretada, mesmo estando implícita. 


\title{
2 MAPEANDO OS CONCEITOS
}

Paul Conway evidencia a importância crucial da gestão de recursos para o êxito da preservação. Segundo ele,

Hoje, preservação é uma palavra que envolve inúmeras políticas e opções de ação, incluindo tratamento de conservação. Preservação é a aquisição, organização e distribuição de recursos, a fim de impedir posterior deterioração ou renovar a possibilidade de utilização de um seleto grupo de materiais (CONWAY), 1997, p 15)

Buscando-se o termo preservação no Dicionário Brasileiro de Terminologia Arquivística, publicado pelo Arquivo Nacional (2005, p.135), encontra-se, "prevenção da deterioração e danos em documentos, por meio de adequado controle ambiental e/ou tratamento físico e/ou químico". Mas o que vem a ser controle ambiental? O controle ambiental inclui o cuidado no manuseio dos documentos? A resposta é sim. A otimização das condições ambientais é obtida basicamente através do controle de alguns elementos, como: temperatura e umidade relativa do ar, níveis de poluentes, higiene rigorosa e luminosidade. Evidentemente, o controle destes elementos não deve ser garantido apenas nos depósitos, há de se controlar também as áreas onde os documentos serão consultados.

Silvana Bojanoski explica que:

\begin{abstract}
A busca de soluções para os problemas de preservação está cada vez mais baseada, por um lado, em conhecimentos tecnológicos e científicos e, por outro, em ações gerenciais voltadas para o desenvolvimento de políticas de preservação dos acervos como um todo (BOJANOSKI,1999, p. 39)
\end{abstract}

As definições encontradas no Dicionário de Ciências Sociais da Fundação Getúlio Vargas para os conceitos de "gerenciamento" ou "gerência" referem-se ao "processo de formular e executar uma política empresarial ou industrial (também podendo ser institucional) através das atividades funcionais de planejamento, organização, direção, coordenação e controle" (FUNDAÇÃO GETÚLIO VARGAS, 1987, p.515).

Interessante também a definição de Gestão de Documentos encontrada na Lei no 8159 de janeiro de 1991, conhecida com Lei de Arquivos, visto que todo o processo desenvolvido para racionalizar o fluxo documental favorece a preservação dos documentos considerados de valor permanente. Conforme essa Lei:

Considera-se gestão de documentos o conjunto de procedimentos e operações técnicas referentes à sua produção, tramitação, uso, avaliação e arquivamento em fase corrente e intermediária, visando a sua eliminação ou recolhimento para guarda permanente (BRASIL, Lei $\mathrm{n}^{\circ} 8.159$, de 8 de janeiro de 1991). 
Contudo, no processo de organização de um programa cujo objetivo é garantir a preservação de acervos, o planejamento é o elemento fundamental. Pois o planejamento é um "método para traçar as metas e os meios de alcançá-las. [...] J. D. Millett (FUNDAÇÃO GETÚLIO VARGAS, p.897) diz que o 'trabalho de planejamento, reduzido talvez a seu aspecto mais elementar, consiste em definir e acentuar os objetivos' [...]. Sendo assim, o planejamento é essencial em qualquer instituição que necessite estabelecer e implementar adequadamente suas políticas, tanto de acesso e preservação, como também nas demais políticas necessárias. Conforme afirma Idalberto Chiavenato (1982. p. 245), “o planejamento consiste na tomada antecipada de decisões sobre o que fazer antes que a ação seja necessária”. Assim, o planejamento é uma das atividades essenciais ao gerenciamento.

Em 1964, Oliver Holmes já alertava para a importância do planejamento no âmbito das ações para preservação. Palestrando sobre as responsabilidades que a Sociedade de Arquivistas Americanos poderia considerar, a exemplo do Conselho para a Preservação dos Arquivos dos Negócios, organizado em Londres em 1934, dizia ele na ocasião:

\begin{abstract}
Planos devem ser igualmente estabelecidos para a preservação de arquivos dos negócios modernos. Através de amostras planificadas e do uso de modernas inovações técnicas, tais como a microfilmagem, existe agora, pela primeira vez, oportunidade de legar ao futuro um quadro adequado dos atuais modos de vida, e isso a despeito da crescente complexidade da idade moderna. Isso, entretanto, só poderá ser conseguido através da fixação de certos objetivos e obtendo-se apoio a fim de alcançá-los. Ouvimos falar muito, nestes dias, de planificação - planificação da agricultura, planificação do uso sábio dos recursos minerais, planificação, em suma, de uma economia completa. Igual planificação será necessária se quiserem conservar para o futuro os recursos acumulados pelas experiências do passado e do presente (HOLMES, 1964, p. 280).
\end{abstract}

Karen Garlick abordando a questão do planejamento no âmbito de programas de manutenção de acervos, comenta:

[...] o planejamento é o elemento mais importante na organização de um programa de manutenção de acervos. Sem um planejamento, os escassos recursos podem ser despendidos em projetos que não refletem as maiores necessidades da preservação nem as prioridades da instituição. Embora o planejamento tome tempo e energia, planos bem concebidos permitem a uma instituição desenvolver projetos de modo coerente e sistemático (GARLICK,1997, p.6).

Sem entrar em detalhes de natureza técnica, percebe-se a importância de um rigoroso diagnóstico das condições físicas do acervo para identificar, por ordem de prioridades, as causas e origens da deterioração e determinar qual será o melhor tratamento a ser adotado, quando e como aplicá-lo. Assim, o conceito de prioridade encontrado no Dicionário Michaelis diz: "qualidade do que está em primeiro lugar. Direito de falar primeiro ou de ser 
atendido em primeiro lugar" (MICHAELIS, 2001). Ou seja, o planejamento exige também a definição do que é institucionalmente prioritário.

Francisco Lacombe em sua obra Dicionário de Administração, esclarece que políticas são:

[...] conjunto de declarações escritas a respeito das intenções da instituição em relação a determinado assunto. As políticas indicam o conjunto sistemático de meios e a forma desejados para atingir os objetivos principais. Se bem estabelecidas e executadas, conduzem a esses objetivos. São formuladas, em geral, de forma ampla e abrangente, não entrando em detalhes, e proporcionam as linhas mestras para orientar tanto as decisões mais importantes, quanto a formulação dos objetivos setoriais e das normas. Uma vez instituídas, tendem a permanecer em vigor por períodos mais ou menos longos. Orientam a formulação dos procedimentos, os quais, em geral, são detalhados e escritos sob a forma de normas. As políticas também são às vezes chamadas de diretrizes (LACOMBE, 2004, p.245).

As políticas podem estar explícitas, ou seja, oficializadas em documentos próprios da instituição, ou implícitas, o que ocorre quando as políticas se caracterizam como:

Práticas genéricas correntes na empresa, que não estão oficializadas nem escritas, mas orientam as decisões dos administradores. Nem todas as empresas escrevem suas políticas. Algumas nunca se dão ao trabalho de fazê-lo. No entanto, mesmo que a empresa não tenha políticas explicitamente definidas, ela sempre as terá de alguma forma implícita, porque deve haver coerência nas decisões da empresa. (LACOMBE, p. 247),

Deste modo, pode-se inferir que caso a instituição não tenha uma política explicita a respeito de cada assunto, suas políticas implícitas podem ser identificadas pelas práticas decisórias utilizadas para resolver certas questões.

Como fala J. Subirats (apud DURÁ, 2002): o processo de elaboração de toda política implica na tomada de uma série de decisões e o estabelecimento de interações entre indivíduos, grupos e instituições. "Decidir que existe un problema. Decidir que se debe intentar resolver. Decidir la mejor manera de resolver. Decidir legislar sobre el tema". Estas decisões e interações serão sempre influenciadas pelas condutas e disposições dos atores envolvidos.

\footnotetext{
Para alcançar essa interação de esforços e identificação com a estratégia empresarial, os planos táticos precisam ser complementados por políticas e diretrizes. Uma política é um guia genérico para a ação. Ela delimita a ação, mas não especifica o tempo. É uma definição de propósitos comuns de uma empresa e estabelece linhas de orientação e limites para a ação dos indivíduos responsáveis pela implementação dos planos. As políticas constituem planos que lidam com problemas recorrentes e para os quais não existe solução rotineira e levam a organização a reconhecer objetivos específicos e a trabalhar em conjunto para seu alcance dentro de uma maneira amplamente definida (CHIAVENATO, p. 245).
}

Todas as atividades da instituição deverão ser permeadas por decisões criteriosamente planejadas e conscientemente tomadas para a consecução dos objetivos institucionais. Logo, 
se o objetivo do arquivo é preservar e dar acesso aos documentos, as decisões tomadas pelo corpo administrativo devem ser orientadas para esta finalidade.

Para Dagnino (2002), convém ainda levar em consideração mais alguns aspectos para melhor entender o conceito de política:

1. A distinção entre política e decisão: a política é gerada por uma série de interações entre decisões mais ou menos conscientes de diversos atores sociais (e não somente dos tomadores de decisão);

2. a distinção entre política e administração;

3. que política envolve tanto intenções quanto comportamentos;

4. tanto ação como não-ação;

5. que pode determinar impactos não esperados;

6. que os propósitos podem ser definidos ex post: racionalização;

7. que ela é um processo que se estabelece ao longo do tempo;

8. que envolve relações intra e inter organizações;

9. que é estabelecida no âmbito governamental, mas envolve múltiplos atores;

10. que é definida subjetivamente segundo as visões conceituais adotadas.

A preservação de acervos é um assunto que engloba a instituição arquivística como um todo. Se por um lado a instituição deve ficar envolvida pela política de preservação, por outro a política de preservação exigirá a contribuição de todos, inclusive dos usuários. Trata-se de um trabalho de gestão, onde o que está em jogo é o planejamento para definição de prioridades de ação.

\section{ASPECTOS GERENCIAIS DA PRESERVAÇÃO DE ACERVOS ARQUIVÍSTICOS}

\section{Insistindo nas palavras de Conway}

O gerenciamento da preservação compreende todas as políticas, procedimentos e processos que, juntos, evitam a deterioração ulterior do material de que são compostos os objetos, prorrogam a informação que contêm e intensificam sua importância funcional. [...] Gerenciamento de preservação envolve um progressivo processo reiterativo de planejamento e implementação de atividades de prevenção (mantendo, por exemplo, um ambiente estável, seguro e livre de perigos, assegurando ação imediata em caso de desastres e elaborando um programa básico de manutenção do nível das coleções) e renovação de atividades [...]. (CONWAY, 1997, p. 6):

Nesta perspectiva, é absolutamente essencial esclarecer a todos os profissionais da instituição, e em especial aos que lidam efetivamente com o acervo, a necessidade de observância às normas e demais gerenciamentos de preservação. Este cuidado visa remover eventuais obstáculos políticos que possam surgir dentro da instituição e converter setores estratégicos em aliados.

Uma prática eficiente de preservação desenvolve-se ao longo desta cooperação bilateral [no caso dos arquivos, entre arquivistas e conservadores], mas é da responsabilidade do departamento de preservação alinhar as prioridades: 
1. seguindo as indicações recolhidas em cada coleção;

2. de acordo com os recursos disponíveis previamente atribuídos; e

3. implementando uma estratégia preventiva contra o anterior conceito de restauro. A preservação é uma responsabilidade global da instituição que deve ser comungada por cada elemento do pessoal, embora, quando toca à ação, esta deva ser da responsabilidade de um único departamento. (CABRAL, 2002, p. 119).

Beck entretanto, parece ter um ponto de vista mais elástico quanto às responsabilidades da preservação dentro da instituição, pois, para ela:

Os projetos de preservação, selecionados a partir da interlocução, ganham relevância institucional e as ações adquirem condições de continuidade. Com esta nova visão gerencial, já não são apenas os conservadores em suas especialidades que decidem o que, como e quando preservar (BECK, 2006, f. 4).

Beck vai além, incluindo os documentos eletrônicos no âmbito das preocupações centrais com a preservação dos registros informacionais:

Desta forma, tão importante como resguardar a evidência dos registros do passado em seus suportes de papel, de filme ou de material fotográfico, é assegurar a sobrevida dos registros em mídias magnéticas e digitais. Por esta razão, preservar informações relevantes requer o envolvimento de equipes multidisciplinares na seleção de preservação, no estabelecimento de prioridades com base no valor informacional, na demanda de uso e na vulnerabilidade de cada tipo de suporte. A partir destes dados, podem ser definidas políticas de custódia e de acesso (2006, p. 44).

Endossando a questão, Conway lembra que as recentes estratégias de gerenciamento de preservação consideram que uma ação de preservação deverá ser aplicada ao acervo com o objetivo precípuo de torná-lo disponível para uso. Embora o axioma de que a preservação e o acesso são atividades relacionadas também prevaleça no discurso deste autor, ele as distingue sob a alegação de que:

É possível atender às necessidades de preservação de uma coleção de manuscritos, por exemplo, sem resolver os problemas de acesso. De maneira semelhante, o acesso a materiais eruditos pode ser garantido por um longo período de tempo, com a adoção de uma ação concreta de preservação. [...] Nesta perspectiva, gerar uma cópia de preservação de um livro deteriorado em microfilme, sem tornar possível sua localização [...], é um desperdício de dinheiro (CONWAY,1997, p. 6-7).

\footnotetext{
Schellenberg adverte que o arquivista é o profissional responsável por formular normas e métodos relativos ao uso de documentos - suportes da informação arquivística, levando em conta os aspectos de preservação dos mesmos. Para ele, o arquivista:

Deve tentar fazer com que se possa dispor do material num máximo compatível com uma estimativa razoável quanto à preservação do mesmo, pesando, de um lado, as solicitações dos consulentes atuais e, do outro, as solicitações da posteridade pela preservação dos documentos (SCHELLENBERG, 2004, p. 353).
} 
No VI Congresso Nacional de Bibliotecários, Arquivistas e Documentalistas, ocorrido na cidade de Aveiro, em 1998, Pedro Peixoto salientou a complexidade do trabalho do arquivista diante da crescente produção informacional. Assim como Schellenberg, Peixoto também atribuiu ao arquivista um papel preponderante, destacando a importância da atuação multidisciplinar no contexto de pesquisa, que pode ser igualmente pertinente no ambiente institucional arquivístico como um todo:

Ao arquivista cabe a complexa tarefa de dar unidade e uniformidade a todo o sistema, equacionando toda a problemática relacionada com a produção de informação em suportes tradicionais e em novos suportes, em constante mudança, o que prenuncia a necessidade inexorável de uma ação multidisciplinar, que ganha particular consistência numa instituição com fins específicos, entre outros, de investigação e desenvolvimento (PEIXOTO, 1998, p. 6).

A preservação dos acervos deve ser percebida como uma atividade matricial, perpassando todos os setores institucionais. Deste modo, o pessoal encarregado do atendimento aos usuários também pode desempenhar um papel relevante na definição de prioridades, indicando quais os documentos mais consultados e, portanto, mais sujeitos ao manuseio e à degradação.

Para Schellenberg, "se há de se estabelecer prioridades quanto ao uso dos documentos, devem estas basear-se no caráter do que se solicita e não de quem o faz" (SCHELLENBERG, p. 353). De modo semelhante, Dan Hazen afirma: "quando precisam ser feitas escolhas, deveria ser conferida alguma prioridade aos materiais que as pessoas efetivamente usam" (HAZEN, 1997, p. 8).

Buscar harmonizar o dilema entre preservação e uso é, por conseguinte, urgente, já que um aspecto não deve sobrepor-se ao outro, muito pelo contrário, ambos devem ser utilizados como auxiliares mútuos em defesa dos direitos dos cidadãos, de hoje e de amanhã, no acesso às informações que lhes sejam de interesse.

Logo, o êxito da preservação em um arquivo requer levar à prática um somatório de decisões e ações para uma correta gestão. Para isto, torna-se fundamental não apenas a parceria entre arquivistas e conservadores, mas o envolvimento de todos os profissionais da instituição arquivística, bem como dos usuários, já que todo o esforço feito para prolongar a vida dos documentos tem como objetivo mantê-los em condições de acesso e uso.

Um bom planejamento é imprescindível para uma acertada estratégia de gestão. A estratégia faz referencia ao modo de utilização dos recursos disponíveis para alcançar os objetivos institucionais. O planejamento resultará em um documento formal, respaldado em 
informações quantitativas e seguras. Este documento sendo fruto do trabalho conjunto das equipes adquire credibilidade institucional e servirá de base para as futuras atividades visando à preservação do acervo.

\title{
4 IMPORTÂNCIA DAS POLÍTICAS PARA USO, ACESSO E PRESERVAÇÃO DOCUMENTAL
}

Garantir "o acesso permanente é o objetivo da preservação, sem ele a preservação não tem sentido, exceto como fim em si mesma" (MEMÓRIA DO MUNDO, 2002, p. 17). Assim, o trabalho em arquivos tem como finalidade preservar os documentos custodiados para tornálos acessíveis à consulta. Todavia, assim como o arquivo, o arquivista também tem a função de preservar os documentos. Logo, seu território de ação é a fronteira do uso dos documentos com a sua preservação.

Salientando o caráter estratégico da política de preservação de patrimônio, Aline Magalhães comenta:

\begin{abstract}
Uma política de preservação de patrimônio pode ser definida de diversas maneiras. Antes de qualquer coisa é um conjunto de ações que visa salvar referências. Pensada dessa forma, qualquer política de preservação é estratégica, pois, salvando referências do desaparecimento, salva identidades. E quanto mais amplas e abrangentes sejam tais identidades, mais importante poderá ser considerada tal política (MAGALHAES, 2004, p.11).
\end{abstract}

Assim, como a própria autora conclui, a preservação de tais referenciais implica, necessariamente, no estabelecimento de uma política formalmente constituída e explícita.

Durante seu discurso no Seminário Arquivos: a segurança e a insegurança dos arquivos e dos arquivistas, ocorrido no Arquivo Nacional do Brasil, em 2007, Ingrid Beck abordou a importância da formalização das políticas de preservação, dizendo: "toda política de preservação tem que estar associada a ações concretas e que devem estar formuladas em um documento como parte integrante de um plano. Se estiver claro na forma de um documento, não há como negar orçamento para isso". ${ }^{1}$

Uma política pública arquivística, no entendimento de Jardim, é caracterizada pelo:

Conjunto de premissas, decisões a ações - produzidas pelo Estado e inseridas nas agendas governamentais em nome do interesse social - que contemplam os diversos aspectos (administrativos, legal, científico, cultural, tecnológico, etc.) relativos à

\footnotetext{
${ }^{1}$ Informação verbal em I Seminário Arquivos: a segurança e a insegurança dos arquivos e dos arquivistas. Rio de Janeiro: Arquivo Nacional. 11/10/2007.
} 
produção, uso e preservação da informação arquivística de natureza pública e privada (JARDIM, 2006. p. 10).

Do mesmo modo que as políticas públicas arquivísticas devem ter interseção com outras políticas públicas, as políticas de acesso ao acervo devem constituir uma das dimensões da política de preservação, que, por sua vez, deverá estar contemplada no seio de uma política arquivística maior, de amplitude institucional.

Schellenberg distingue política de acesso e política de uso. Para ele, esta teria como objetivo a proteção dos interesses privados e a segurança do Estado, enquanto que a política de uso, embora relacionada, estaria voltada para a preservação dos documentos. O autor cita o exemplo do Arquivo Nacional dos Estados Unidos da América onde:

Para estabelecer a política de regulamentação quanto ao acesso aos documentos públicos que satisfaça tanto aos funcionários quanto ao publico em geral, é necessário esboçar normas para determinar e impor restrições no uso dos documentos. [...] a 'declaração de restrição' é um documento de uma página, podendo, em certos casos, desdobrar-se em várias. As declarações são emitidas em papel de cor diferente a fim de chamar a atenção dos funcionários quanto à proibição do uso de documentos com que estejam trabalhando. As declarações são também publicadas nos instrumentos de busca do Arquivo Nacional. Esse processo serve para cristalizar os critérios de acesso aos documentos (SCHELLENBERG, p. 346).

Evidentemente tais impedimentos de acesso devem condicionar-se a um período de tempo determinado, de modo a permitir que os documentos preservados sejam, em seu tempo, devidamente abertos à consulta de todos. Prosseguindo, Schellenberg ainda adverte que uma política de acesso limitado é inviável de ser ministrada com justiça e seu mérito é duvidoso, pois o uso de documentos públicos deve ser facilitado sem se considerar a pessoa ou o seu objetivo. Se o princípio da igualdade não servir de leme ao arquivista, este incorre no sério risco de favorecer tão somente aos "historiadores da corte" (SCHELLENBERG, p. 350). Uma política de privilégios é incompatível com os preceitos democráticos.

Com relação à política de uso dos documentos, Schellenberg ressalta a propriedade do Estado sobre os documentos públicos, de onde se depreende que todos os cidadãos que coletivamente constituem o Estado têm o direito de usar tais documentos, contudo, sem danificá-los.

Os direitos dos cidadãos como co-proprietários, entretanto, não chegam ao ponto de permitir-lhes, individualmente, usar os documentos de uma maneira prejudicial para os documentos. A propriedade do povo deve ser fielmente preservada pelos encarregados de sua custódia oficial de modo que possa ser usada pelas gerações presentes, bem como pelas futuras" (SCHELLENBERG, p. 353. Grifos nossos).

Para o autor, é possível ainda estabelecer prioridades quanto ao uso dos documentos, desde que tais prioridades baseiem-se não em quem solicita, mas sim no quê se solicita, sendo os 
pedidos atendidos na ordem de chegada no Serviço de Referência. Parece legítimo priorizar o atendimento aos cidadãos em busca de comprovações de seus direitos legais ou civis. Por exemplo, se um cidadão solicita o desarquivamento de seu prontuário médico para auxiliar o diagnóstico de uma doença fatal, por que não priorizar o atendimento a este usuário em detrimento temporário de outro que realiza uma pesquisa com fins acadêmicos? Enfatizando, no entanto, que o detrimento seria temporário, ou seja, tão logo fosse possível, este pesquisador seria prontamente atendido. Afinal, todos merecem a mesma consideração e respeito.

Schellenberg também admite certa dose de atenção especial aos pesquisadores cujos trabalhos terão relevância significativa no aumento do conhecimento ou ainda para favorecer sua disseminação. Neste caso, pode-se estar diante de um quadro altamente problemático, pois, de modo geral, os pesquisadores tendem a considerar seus trabalhos dignos de tamanha relevância a ponto de exigirem total atenção por parte dos arquivistas, reivindicando prioridades individuais absolutas. Ora, se o arquivista for dar prioridade a todos, sem exceção, evidentemente, ninguém terá prioridade ou todos terão prioridades iguais, o que de um modo ou de outro comprometerá a qualidade do serviço, uma vez que o processo dialético entre o arquivista e os pesquisadores se inviabiliza. A articulação entre domínio teórico da área arquivística, equilíbrio e bom senso é imprescindível na aplicação de políticas neste contexto.

Na visão de Chiavenato, uma política geralmente deve apresentar maior flexibilidade do que outros tipos de planos. Pois:

Seu propósito não é o de obter absoluta uniformidade de ação, mas de guiar as pessoas que devem desenvolver outros tipos de planos a fim de que elas saibam quando fazer exceções às práticas usuais e quando não fazê-las. [...] À medida que se caminha das políticas aos procedimentos e regras, os limites tornam-se gradativamente mais estreitos e menos sujeitos a interpretação pessoal (CHIAVENATO, p. 246).

Tendo em vista que as políticas deverão nortear os procedimentos de acesso e uso dos documentos, os acervos podem ser disponibilizados de várias maneiras. Segundo Schellenberg:

Conquanto se devam liberar os arquivos para uso, há necessidade de protegê-los quando da sua utilização. Os arquivistas devem observar certas normas ao lidarem com os pesquisadores. Devem solicitar-lhes: a) que se identifiquem; b) que acusem, assinando recibo, a entrega dos documentos cedidos, a fim de assegurar uma garantia pelos mesmos; e c) que se familiarizem com os regulamentos relativos ao uso dos próprios arquivos. [...] Nada há de burocrático na exigência de que o pesquisador forneça informações sobre sua identidade [...]. Cabe ao arquivista solicitar a todo pesquisador, sem considerar quão importante possa o mesmo ser, ou julgar-se, que se familiarize com o regulamento do arquivo relativo ao uso dos documentos. Um pesquisador verdadeiramente importante não fará objeção à 
observância de regras sensatas, formuladas [essencialmente] para preservar as fontes culturais que utiliza" (SCHELLENBERG, p. 354-355).

Nos Estados Unidos, as normas que regulamentam o uso dos arquivos federais são publicadas no Diário Oficial e possuem força de lei, tendo como objetivos:

a) proteger os documentos contra danos físicos que possam advir: do uso de vários tipos de prendedores de papel, de serem dobrados ou de trato indevido; de fumar ou comer ao mesmo tempo que se usam os documentos, ou de se empregarem substâncias químicas fotográficas perto dos mesmos; e, b) proteger os documentos contra todos os atos que possam prejudicar a integridade dos mesmos, tais como darlhes uma ordem diferente, alterá-los ou escrever nos mesmos (SCHELLENBERG, p. 355).

Estas medidas objetivam proteger os acervos, visto que alguns podem ter elevado valor monetário, muito embora o que realmente interessa é o valor cultural do acervo, algo que não se pode mensurar. Comparadas às facilidades que as instituições arquivísticas oferecem aos pesquisadores, certas regras propostas hão de ser facilmente digeríveis.

Certos pedidos podem ser criteriosamente negados. Dentre esses, encontram-se pedidos de pessoas que procuram informações que podem ser devidamente atendidas pelo uso de materiais publicados [...]. O arquivista não deve, normalmente, prestar informações sobre materiais de bibliotecas, mesmo a pessoas que se ocupem de importantes projetos de pesquisas, podendo, no entanto, dar sugestões bibliográficas gerais, desde que para isso não necessite fazer pesquisa especial ((SCHELLENBERG, 356).

Por último, Schellenberg adverte que o arquivista "é empregado para ser um arquivista e não um pesquisador" (SCHELLENBERG, p. 355), caso execute pesquisas com interesse particular, deverá fazê-las em caráter não oficial. Seus deveres profissionais não devem subordinar-se aos seus interesses pessoais.

\section{CONSIDERAÇÕES FINAIS}

Ao realizar este estudo, movia-nos uma inquietude: entender as implicações que a inexistência de uma política arquivística de acesso formalmente constituída e explícita poderia ter no âmbito da preservação documental. Como visto, as políticas arquivísticas existem para dar respostas a problemas políticos no universo arquivístico.

A inexistência de uma política arquivística de acesso formalizada pode ter sérias implicações na preservação de acervos, pois o conceito política remete a direção, um caminho a ser seguido e constituem balizamentos ao comportamento dos atores envolvidos no serviço. Assim, se não há um guia que oriente o planejamento das decisões a serem tomadas, estas 
decisões acabam sendo tomadas muito mais ao sabor do acaso ou da interpretação pessoal, do que do conhecimento e da elaboração consciente em prol da missão institucional.

Ainda que nunca se possa atingir a perfeição, é legítimo tentá-lo. Deste modo, acredita-se que seja possível alcançar o equilíbrio no binômio Acesso - Preservação. Embora sejam atividades a priori antagônicas, não são nem podem ser excludentes, muito pelo contrário. A partir do percurso de estudo trilhado, chegamos à conclusão de que acesso e preservação documental afetam-se reciprocamente de múltiplas maneiras, dependendo, em grande parte, das características especificas das políticas arquivísticas adotadas e de como a instituição decide e/ou decidirá pela adoção e implementação de tais políticas.

Se dar acesso aos acervos documentais é primordial, então o planejamento na preservação destes acervos também deverá ser. Sem planejamento não há como visualizar e determinar ações futuras que conduzam aos objetivos institucionais concernentes à proteção dos acervos. Visto por este ângulo, o planejamento pode ser mais que uma atividade essencial ao gerenciamento: pode ser a principal ferramenta de gestão no processo de formulação e execução de políticas.

Uma política de preservação não se define de modo isolado. Serão envolvidos elementos diversos, contraditórios ou convergentes, permeando toda a instituição, seus acervos e seus atores.

Em preservação documental não existe uma regra definitiva e que atenda a todos os casos. É imprescindível lançar mão de estratégias de gestão que levem em consideração as especificidades e prioridades institucionais. Mesmo que o acervo seja composto por documentos únicos e insubstituíveis, as prioridades deverão ser muito bem identificadas, pois a preservação integral é uma tarefa impossível até mesmo nas instituições mais abastadas. As estratégias de preservação deverão ser implementadas de acordo com o perfil especifico da instituição de custódia, dos usuários e dos tipos de materiais que serão preservados. Para ser bem sucedido, é fundamental que o programa de preservação esteja inserido num contexto maior, no âmbito de uma política de gestão arquivística, atentando para os critérios de avaliação documental e demais aspectos técnicos do acervo.

Os acervos custodiados são, na verdade, patrimônio do Estado. E o público, seja o acadêmico, o pesquisador, ou ainda outro perfil, que venha a surgir é, em essência, um contribuinte, um cidadão que paga impostos e que, portanto, está no exercício de seu direito de acesso e dever de uso consciente da coisa pública. Mas se estamos propondo que a instituição assuma que 
seu público consulente deverá ter suas demandas devidamente atendidas, assumir a custódia responsável parece imanente. Porém, será que as instituições estão prontas para a magnitude deste objetivo?

Como vimos ao longo deste estudo, o trabalho do arquivista não é fácil. Exige conhecimentos teóricos, reflexão, muito debate e, na medida do possível, a busca pelo consenso. Preservar para dar acesso e dar acesso garantindo a preservação. Este dilema, sem dúvida, remete a um patamar político.

\section{REFERÊNCIAS}

ARQUIVO NACIONAL (Brasil). Dicionário Brasileiro de Terminologia Arquivística. Rio de Janeiro: Arquivo Nacional, 2005. 232p.

BECK, Ingrid. O ensino da preservação documental nos cursos de Arquivologia e Biblioteconomia: perspectivas para formar um novo profissional. 2006. Dissertação (Mestrado em Ciência da Informação) - Universidade Federal Fluminense/Instituto Brasileiro de Informação em Ciência e Tecnologia, Rio de Janeiro: 2006. 109 f.

. Dois aspectos da formação em preservação documental. Arquivo \& Administração, Rio de Janeiro, v. 5, n. 2, p. 43-52, jul./dez. 2006.

A importância do planejamento de preservação. Arquivo \& Administração, Rio de Janeiro, v. 4, n. 1, p. 19-30, jan./jun. 2005.

BELLOTTO, Heloisa Liberalli. Arquivos permanentes: tratamento documental. 2. ed. rev. e ampl. Rio de Janeiro: FGV, 2004. 320 p.

BOJANOSKI, Silvana. Estudo sobre condições de preservação dos acervos documentais brasileiros. Arquivo \& Administração, Rio de Janeiro, v. 2, n.1/2, p. 35-78, jan./dez.1999.

BRASIL. Constituição da República Federativa do Brasil. Promulgada em 05 de outubro de 1988. Disponível em:

$<$ http://www.planalto.gov.br/ccivil_03/Constituicao/Constitui\%C3\%A7ao.htm>. Acesso em: 19/07/07

. Lei $\mathbf{n}^{\mathbf{0}}$ 8.159, de 8 de janeiro de 1991. Dispõe sobre a política nacional de arquivos públicos e privados. Disponível em:

$<$ http://www.conarq.arquivonacional.gov.br/cgi/cgilua.exe/sys/start.htm>. Acesso em: 02/07/07.

CABRAL, Maria Luísa. Amanhã é sempre longe demais: crônicas de Preservação e Conservação. Lisboa: Gabinete de Estudos a\&b, 2002. 199 p.

CHIAVENATO, Idalberto. Administração de empresas: uma abordagem contingencial. São Paulo: McGraw-Hill do Brasil, 1982. 606 p.

CONWAY, Paul. Preservação no universo digital. Rio de Janeiro: Projeto Conservação Preventiva em Bibliotecas e Arquivos: Arquivo Nacional, 1997. 24 p. 
DURÁ, Jaime Ferri. Políticas Públicas. In: Román Reyes (Dir): Diccionario Crítico de Ciencias Sociales. Madri: Pub. Electrónica, Universidad Complutense, 2002. Disponível em: $<$ http://www.ucm.es/info/eurotheo/diccionario>. Acesso em: 24/11/2007.

FONSECA, Maria Odila. Arquivologia e ciência da informação. Rio de Janeiro: FGV, 2005. $121 \mathrm{p}$.

FUNDAÇÃO GETÚLIO VARGAS; INSTITUTO DE DOCUMENTAÇÃO. Dicionário de Ciências Sociais. Benedito Silva (Coord. geral). 2. ed. Rio de Janeiro: FGV, 1987. 1422 p.

GARLICK, Karen. Planejamento de um programa eficaz de manutenção de acervos. In: CADERNO técnico: planejamento e prioridades. Rio de Janeiro: Projeto Conservação Preventiva em Bibliotecas e Arquivos: Arquivo Nacional do Brasil, 1997. p. 16.

HAZEN, Dan C. Desenvolvimento, gerenciamento e preservação de coleções. In: PLANEJAMENTO de preservação e gerenciamento de programas. Rio de Janeiro: Projeto Conservação Preventiva em Bibliotecas e Arquivos: Arquivo Nacional, 1997. p. 8.

HOLLÓS, Adriana Cox. Entre o passado e o futuro: os limites e as possibilidades da preservação documental no Arquivo Nacional do Brasil. 2006. Dissertação (Mestrado em Memória Social) - Universidade Federal do Rio de Janeiro, Rio de Janeiro, 2006. 99 f.

HOLMES, Oliver W. A avaliação e preservação dos arquivos de negócios. In: JAMESON, Samuel Haig (Comp.). Administração de arquivos e documentação. Rio de Janeiro, FGV. 1964. p. 280.

JARDIM, José Maria. Políticas públicas arquivísticas: princípios, atores e processos. Arquivo \& Administração, Rio de Janeiro, v. 5, n. 2, p. 5-16, jul./dez. 2006.

O inferno das boas intenções: legislação e políticas arquivísticas. In: MATTAR, Eliana. (Org.). Acesso à informação e política de arquivos. Rio de Janeiro: Arquivo Nacional do Brasil, 2003. p. 37-45.

LACOMBE, Francisco José Masset. Dicionário de administração. São Paulo: Saraiva, 2004. $358 \mathrm{p}$.

MAGALHAES, Aline Montenegro. A curta trajetória de uma política de preservação patrimonial: a inspetoria de monumentos nacionais, 1934-1937. Anais do Museu Histórico Nacional, v. 36, 2004. p.9-18.

MEMÓRIA DO MUNDO. Diretrizes para salvaguarda do patrimônio documental. ed. rev. Paris: UNESCO, 2002. 67 p. Disponível em: $<$ http://www.portalan.arquivonacional.gov.br/Media/Diretrizes\%20para\%20a\%20salvaguarda \%20do\%20patrimônio\%20documental.pdf>. Acesso em: 26/11/2007.

MENDONÇA, Eliana Rezende Furtado de; RAMALHO, Lucia Carpi. A política de acesso do Arquivo Público do Estado do Rio de Janeiro ao acervo DOPS. Arquivo e História, Rio de Janeiro, n. 3, p. 6, out. 1997.

MICHAELIS. Moderno dicionário da língua portuguesa. São Paulo: Editora Melhoramentos, 2001. CD-ROM.

PAES, Marilena Leite. Arquivo: teoria e prática. 3. ed. rev. ampl. reimp. Rio de Janeiro: FGV, 2004. 228 p.

PEIXOTO, Pedro de Abreu. Da cooperação institucional das instituições de ensino superior em Portugal - para uma estratégia global na abordagem do futuro da arquivística. In: 
Congresso Nacional de Bibliotecários, Arquivistas e Documentalistas, 6. 1998, Aveiro, Anais ... Aveiro, 1998. p. 6.

SCHELLENBERG, Theodore R. Arquivos modernos: princípios e técnicas. 4 ed. Rio de Janeiro: FGV, 2004. 388 p.

SILVA, Maria Celina Soares Mello e. Arquivos científicos: referências bibliográficas. Rio de Janeiro: Museu de Astronomia e Ciências Afins, 2005. 39 p. Disponível em: $<$ http://www.mast.br/downloads/arquivos_cientificos_bibliografia.pdf $>$. Acesso em: 28/10/2007.

SILVA, Sergio Conde Albite. Algumas reflexões sobre preservação de acervos em arquivos e bibliotecas. Rio de Janeiro: Academia Brasileira de Letras, 1998. 34 p.

\begin{abstract}
The work discusses the implications of the inexistence of archive policies for the preservation of documentary collections. It assumes that documentary preservation aims at assuring the access to and the use of documents, as the inappropriate handling during a research is considered as one of the several deteriorating factors that affect collections. Existing difficulties in this field are mentioned and documentary preservation is presented as a managerial work whose main point is the planning for defining action priorities.
\end{abstract}

Keywords: Documentary preservation. Archive policies. Access. Use. Archivology.

Originais recebidos em: 03/10/2010

Aceito para publicação em: 15/12/2010 